Review paper

\title{
Monte Carlo-based patient internal dosimetry in fluoroscopy-guided interventional procedures: A review
}

\author{
Wilbur K.S. Fum ${ }^{\text {a, b, *, Jeannie Hsiu Ding Wong }}{ }^{\text {a,*, }}$, Li Kuo Tan ${ }^{\text {a,* }}$ \\ ${ }^{a}$ Department of Biomedical Imaging, Faculty of Medicine, University of Malaya, Kuala Lumpur 50603, Malaysia \\ ${ }^{\mathrm{b}}$ Division of Radiological Sciences, Singapore General Hospital, Outram Rd, Singapore 169608, Singapore
}

\section{A R T I C L E I N F O}

\section{Keywords:}

Interventional radiological procedures

Patient organ dosimetry

Fluoroscopy-guided

Monte Carlo methods

\begin{abstract}
A B S T R A C T
Purpose: This systematic review aims to understand the dose estimation approaches and their major challenges. Specifically, we focused on state-of-the-art Monte Carlo (MC) methods in fluoroscopy-guided interventional procedures.

Methods: All relevant studies were identified through keyword searches in electronic databases from inception until September 2020. The searched publications were reviewed, categorised and analysed based on their respective methodology.

Results: Hundred and one publications were identified which utilised existing MC-based applications/programs or customised MC simulations. Two outstanding challenges were identified that contribute to uncertainties in the virtual simulation reconstruction. The first challenge involves the use of anatomical models to represent individuals. Currently, phantom libraries best balance the needs of clinical practicality with those of specificity. However, mismatches of anatomical variations including body size and organ shape can create significant discrepancies in dose estimations. The second challenge is that the exact positioning of the patient relative to the beam is generally unknown. Most dose prediction models assume the patient is located centrally on the examination couch, which can lead to significant errors.

Conclusion: The continuing rise of computing power suggests a near future where MC methods become practical for routine clinical dosimetry. Dynamic, deformable phantoms help to improve patient specificity, but at present are only limited to adjustment of gross body volume. Dynamic internal organ displacement or reshaping is likely the next logical frontier. Image-based alignment is probably the most promising solution to enable this, but it must be automated to be clinically practical.
\end{abstract}

\section{Introduction}

Rapid advances in biomedical imaging technologies have dramatically improved diagnosis and treatment in interventional radiological procedures. However, it has also led to increased concerns of radiation safety, especially transcatheter therapy that can require extended durations of fluoroscopy, which could result in high levels of radiation dose to patients, and subsequently causing serious injury.

The use of ionising radiation for fluoroscopy-guided interventions can result in two types of radiation risks: stochastic risk of induced neoplasia, and deterministic risks for superficial tissues such as skin or the eye lens [1-6]. The severity of superficial tissue injury increases with the dose received, from transient erythema, extending to dermal atrophy, induction, and ulceration at long term reactions [7].
Unlike skin injuries which can be seen directly, the damage to internal radiosensitive organs is virtually unobservable. Most existing radiation-induced risk models for internal organs were primarily based on epidemiological studies in therapeutic energy ranges [8-10]. But evidence from experimental and epidemiological studies have shown unexpectedly high incidences of injury after exposure to lower doses, examples include cataracts and circulatory disease [11]. This resulted in the acute threshold dose being revised to $0.5 \mathrm{~Gy}$ (or $500 \mathrm{mSv}$ ) in 2012 [11]. However, this $0.5 \mathrm{~Gy}$ threshold could still be easily reached during complex procedures involving long fluoroscopy times.

In general, internal organ dosimetry can be either conducted via physical measurement using solid phantoms with embedded dosimeters, or post-exam estimation using computational phantoms and software simulation [12]. Patient-specific physical measurement is infeasible due

\footnotetext{
* Corresponding authors at: Department of Biomedical Imaging, Faculty of Medicine, University of Malaya, Kuala Lumpur 50603, Malaysia.

E-mail addresses: fum.kok.sheong@sgh.com.sg (W.K.S. Fum), jeannie_wong80@um.edu.my (J.H.D. Wong), lktan@um.edu.my (L.K. Tan).
} 
to the impracticality of performing direct internal measurements on patients. Due to the dynamic nature of interventional procedures, practical estimation of patient's internal organ dose largely utilises dose mapping or Monte Carlo methods.

Monte Carlo methods demonstrate greater feasibility for clinical dose estimation as it can precisely simulate the complex radiation interactions and energy depositions in the human body. Though heavily processor intensive, the simulations can be accelerated with graphics processing units (GPU) [13]. The continuing rise of computing power suggests a near future where Monte Carlo methods become practical for routine clinical dosimetry [14]. In this systematic review, we explore state-of-the-art Monte Carlo dosimetry approaches in interventional radiological procedures and summarise the performance of current methods. This should enable insight to potential research gaps.

The literature search methodology is presented in Section 2. In Section 3, we review the literature of radiation dose estimation approaches in fluoroscopy-guided interventional procedures, and the major challenges linked to these approaches. In Section 4, we focus on Monte Carlo approaches with regard to the basic components of Monte
Carlo simulation. In Section 5, we discuss about the challenges in accurate simulation of clinical procedures. In Section 6, we summarise the key findings, perceived challenges, research gaps, and future trends for interventional radiology dosimetry.

\section{Materials and methods}

\subsection{Search methodology}

A literature search was performed on PubMed (MEDLINE), EBSCOhost (CINAHL), Web of Science, and Science Direct databases for full journal articles or abstracts from inception until 22 September 2020. Fig. 1 shows the flow chart of the literature search strategy.

The searches each combined relevant keywords and medical subject headings (MeSH) with minor variations specific to each database. The keywords used included combinations of generic terms describing fluoroscopy guided interventional procedures, and specific terms describing radiation risk quantities. We included vascular, cardiac and neuro interventions to cover the three major interventional specialties of

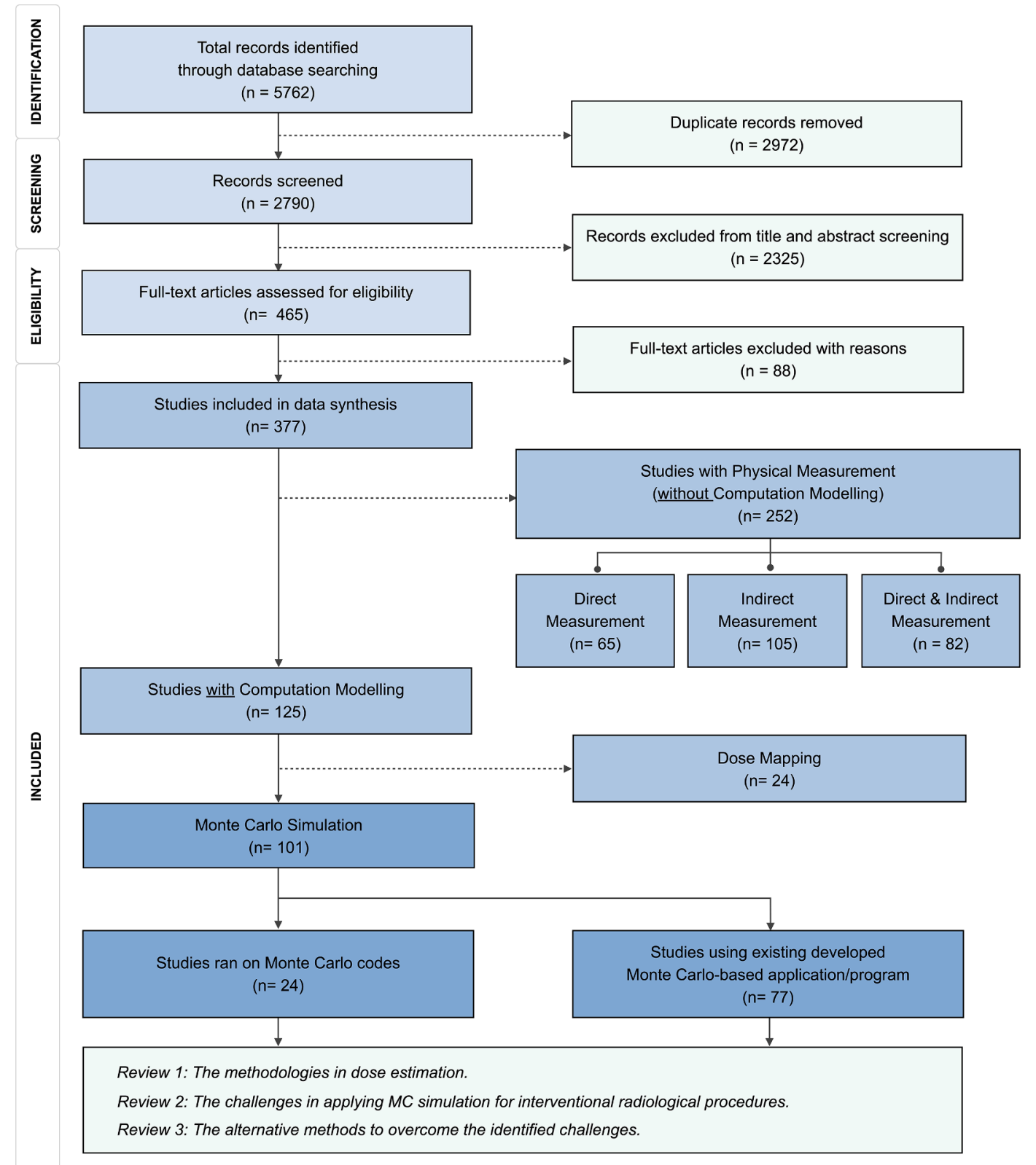

Fig. 1. Flow chart diagram of literature assessment. 
vascular interventional radiology, interventional cardiology, and interventional neuroradiology. Details of the search strategy is provided in Supplementary Material.

Only studies published or translated in English were selected. Reviews, commentaries, magazines, and letters were excluded. Articles were only included if they were full journal articles or abstracts that clearly described the methodology used for radiation dosimetry. This review only included fluoroscopy-guided interventional radiological procedures on C-arm fluoroscopy/angiography units. Studies done on conventional computated tomography scanners were excluded from this review.

\subsection{Search outcome, title, and abstract screening}

Our initial systematic search returned 5762 articles. 2790 studies remained after screening for duplicates. Search results were imported into EndNote Version X9.2 (Clarivate, Philadelphia, United States). Records were initially screened by two reviewers based on the title and abstract. 465 papers met the inclusion criteria for full-text screening. All articles identified for full-text screening were obtained in full.

\subsection{Full-text articles review}

All the full-text articles were assigned a unique ID and were screened independently by two reviewers using the inclusion and exclusion criteria listed in "Eligibility Criteria" (List 1.). Ultimately, dual screening identified 377 papers which met our criteria for qualitative synthesis. All the papers were full journal articles.

List 1. Criteria for inclusion and exclusion studies.

(a) Inclusion criteria:

- Interventional procedures including neuro-interventions, cardiac interventions, and vascular interventions, using fluoroscopy-guided units for assessment of patient's venous/arteries.

- Both retrospective and prospective studies.

- The articles clearly stated how the dosimetry measurement/estimation/evaluation were conducted.

- Studies were conducted on either adult or paediatric human subjects, and/or simulated clinical procedures on anthropomorphic phantoms/virtual phantoms.

- Studies proposed new methods on patient dose measurement/estimation for patients undergoing interventional radiological procedures.

\section{(b) Exclusion criteria:}

- Studies focused on the radiation dose from therapeutic radiological procedures such as liver radio-embolisation using radioisotopes.

- Studies without a clear description of how the radiation dose was measured/ estimated/ evaluated.

- Studies which did not clearly state the type of dosimetry equipment used.

- Studies on general non-interventional fluoroscopy procedures such as barium studies, barium swallow, video-fluoroscopic swallowing etc.

- Studies mainly focused on dose affecting image quality.

- Studies using animals as the subject.

- Studies based on conventional computed tomography (CT)/cone beam CT scanners.

- Studies mainly focused on radiation effects on DNA.

- Studies mainly focused on establishment of diagnostic reference levels.

- Studies mainly focused on dosimeter characterisation.

- Studies related to dose reduction/optimisation of an existing protocol, and/or development of a new protocol.
- Studies focused on factors/parameters influencing/affecting radiation dose.

- Studies focused on occupational dose/staff dose/personnel dose management.

- Comparison/review studies of dosimeters/dose monitoring systems.

- Studies focused on foetal dose estimation.

- Studies involving urology procedures.

\subsection{Synthesis and analysis}

Manual assessment of all 377 full-text articles was undertaken, where each paper was tagged with one or more classifications depending on their approach in dose estimation (Table 1). The following definitions were used:

(i) Physical dose measurement refers to radiation dose measurement using physical dosimeters. These were broken down into sub-categories of direct or indirect measurement.

(ii) Dose estimation through computational modelling refers to methods involving modelling of the patient dose using computational models such as Monte Carlo simulation. The approach involves the use of computational models to simulate the process of photon-matter interactions given a specific set of input parameters.

Based on the definition above, 125 papers utilised computational modelling to estimate the radiation dose; either by proposing new concepts, new theoretical modelling constructs, or by using existing software packages. Based on their methodology, these papers are then categorised into two major groups: (1) Dose mapping $(n=24)$ which is commonly used for skin dose estimation, and (2) Monte Carlo simulation $(n=101)$ which is more applied to internal organ dose estimation.

\section{Overview of patient dosimetry in fluoroscopy-guided interventional procedures}

\subsection{Physical measurement}

Adopting the definition of the International Atomic Energy Agency (IAEA) [12], physical measurement can be categorised into two general approaches:

(i) direct measurement on the patients or phantoms, in which the measured data/parameters directly relate to either stochastic or deterministic effects (tissue reaction),

(ii) indirect measurement on the patients or phantoms, in which freein-air measurements are used to characterise X-ray output, which is then scaled via determined exposure factors to reflect the patient dose.

Table 1

The full-text articles classified by their approaches to dose estimation.

\begin{tabular}{|c|c|c|}
\hline & $\begin{array}{l}\text { No computational } \\
\text { modelling }\end{array}$ & $\begin{array}{l}\text { With computational } \\
\text { modelling }\end{array}$ \\
\hline \multicolumn{3}{|l|}{$\begin{array}{l}\text { (1) Physical dose } \\
\text { measurement }\end{array}$} \\
\hline a. Direct measurement & 65 & 1 \\
\hline b. Indirect measurement & 105 & 102 \\
\hline $\begin{array}{l}\text { c. Both direct and indirect } \\
\text { measurement }\end{array}$ & 82 & 20 \\
\hline $\begin{array}{l}\text { (2) No physical dose } \\
\text { measurement }\end{array}$ & - & 2 \\
\hline Total publication & 252 & 125 \\
\hline
\end{tabular}




\subsubsection{Direct measurement (in-vivo)}

As defined, direct measurement can be conducted by either placing the dosimeter on the patient's skin surface or inserting it within an anthropomorphic phantom. Various dosimeters have been used in the literature, such as TLD (thermo-luminescent dosimeter), OSLD (optically stimulated luminescent dosimeter), RPLGD (radio-photoluminescent glass dosimeter), MOSFET(Metal-oxide-semiconductor field-effect transistor), MOSkin detector, thin-film detector, and radiochromic film [15-21].

To evaluate the dose of an individual patient via the direct method, the dosimeters are generally placed on the surface of the patient. Therefore, this approach only directly reflects the skin dose, though it can also be used to roughly estimate internal organ doses.

In contrast, internal organ doses can be directly measured using tissue-equivalent anthropomorphic phantoms such as the Alderson RANDO phantom, by mimicking the clinical procedures [22]. The design of the phantom allows measurement of internal organ doses by inserting the dosimeters in prepared holes within specified organs of interest. The measured tissue/organ equivalent dose $\left(\mathrm{H}_{\mathrm{T}}\right)$ is then computed.

Direct phantom measurement is suitable for retrospective analysis and dose validation studies. However, commercialised solid phantoms have a limited variety of body sizes and do not fully reflect the diversity of the human population. Hence, these measurements are based on the assumptions of standard patient body size, weight, and organ shapes.

\subsubsection{Indirect measurement}

The indirect approach generally refers to measurements made with Kerma-area product (KAP) meters, either with the meter attached to the $\mathrm{X}$-ray tube housing or integral to the equipment. The measurement can be conducted during actual clinical procedures, or separately on a phantom [23-25].

As part of safety requirements [26,27], all fluoroscopy units used in interventional suites that were manufactured after June 2006 are equipped with KAP meters to display reference air kerma $\left(\mathrm{K}_{\mathrm{a} . \mathrm{r}}\right)$ and reference air kerma rate $\left(\mathrm{K}_{\mathrm{a}} \mathrm{r}\right.$ rate). Other indirect estimates of exposure include fluoroscopy time (FT), KAP (previously known as dose area product (DAP)), and cumulative air kerma (CAK).

\subsection{Dose estimation using computational modelling}

\subsubsection{Dose mapping method}

Dose mapping is usually applied for external organ dose estimation, primarily the skin dose. A variety of proposed skin dose mapping techniques utilise the indirect dose metrics (such as KAP) obtained during the clinical examination, and project them onto three-dimensional (3D) models $[28,29]$.

In the past few years, such skin dose mapping systems have been widely implemented in clinical angiography units. These software-based mapping tools either operate in real-time or offline, and include CareGraph (Siemens Healthineers AG, Erlangen, Germany), Dose Tracking System (DTS) (Canon Medical Systems Corporation, Tochigi, Japan.), Skin Dose Map (SDM) (Philips Healthcare, Amsterdam, Netherlands), Em.Dose (Esprimed SAS, Villejuif, France), Dose Map (GE Healthcare, Illinois, United States), and NEXO [DOSE] (Bracco Injeneering S.A., Lausanne, Switzerland) [30-35]. There are also some algorithms and software tools developed for research such as UF-RIPSA algorithms by University of Florida (Florida, United States) and software by Mayo Clinic (United States) $[28,29]$.

The earliest skin dose mapping systems used simple geometric models, where the dose distribution was depicted onto graphical twodimensional (2D) planes, together with the application-specific quantities (fluoroscopy time, KAP reading and CAK values) [30]. Newer dose mapping systems take into consideration back-scattered radiation, massenergy absorption coefficient, and table attenuation when estimating skin doses from the KAP reading. The $2 \mathrm{D}$ dose distribution is usually projected onto a 3D anthropomorphic model, with a colour scale representing the skin dose.

\subsubsection{Monte Carlo (MC) method}

The Monte Carlo method is also known as the stochastic simulation method. It is a numerical technique used to estimate unknown outcomes that cannot be easily solved analytically, through numerous iterations of random sampling. In the context of radiation physics, MC utilises random numbers and probability distribution functions to simulate radiation transmission inside a medium. Through repeated random simulation, numerous photons' or particles' position, energy, direction, and path length (including their physical interactions) can be determined, including their final energy deposition. These individual simulation outcomes are then integrated to evaluate the summative radiation dose in defined volumes [36-38].

\section{Virtual equipment configuration and geometry in Monte Carlo simulation}

In medical radiation dosimetry research, MC simulation is often used to model the radiation dose received by patients during clinical examinations. By simulation of virtual patient or phantom models using the radiation transport codes, it helps to understand the impact of radiation risk and dose uncertainty that cannot be easily measured through physical measurement.

The term "phantom" here usually describes a physical construct which simulates or mimics the radiation transport conditions of the human body. It can be as simple as a water tank or a uniform block of water equivalent material, to one that is shaped resembling a human body to simulate the internal tissue inhomogeneities and contours; an anthropomorphic phantom.

In MC computational modelling, "phantoms" refer to a virtual or computational-based anatomical model that mathematically defines a three-dimensional object, mimicking human tissue radiation transport conditions. The basis of a MC system for patient dosimetry thus consists of two main components: (i) a computational anatomical model represented by solid-geometry which defines the internal and external features of the human body, and (ii) the physical transport of the particles, coded by the MC toolkit, to simulate the passage of radiation photons and particles through the computational phantom.

\subsection{The computational phantom}

Beginning in the 1960s, medical computational phantoms have evolved from geometric quadratic equation designs, to voxelised phantoms created directly from the segmentation of medical images, to anatomical models utilising B-splines or non-uniform rational B-splines (NURBS) for representing curvature, or polygon meshes $[39,40]$.

In general, computational phantoms are categorised based on their modelling technique. There are two general approaches used in solidgeometry modelling: Constructive Solid Geometry (CSG) and Boundary Representative (BREP) [41], as illustrated in Fig. 2. CGS modelling builds the phantom model using elementary geometric shapes such as cubes and cylinders, examples of which include stylised and voxel phantom. BREP modelling defines boundaries rather than volumes and includes phantom models utilising NURBS and polygonal mesh surfaces.

Adopting the classification used by the community, medical computational phantoms thus are classified as:

(a) Stylised phantoms refers to CSG phantoms based on quadric surfaces manipulated through Boolean algebra [42]. Anatomical structures such as the skeleton and internal organs, are represented by relatively simple combinations of geometric shapes.

(b) Voxel phantoms are generally constructed from tomography images, either CT or magnetic resonance imaging (MRI) of patients, or cross-sectional photographs of cadavers [43-46]. The 
(a)

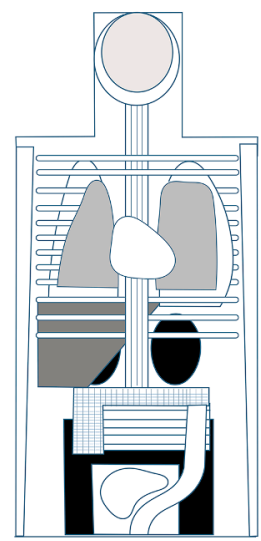

(b)

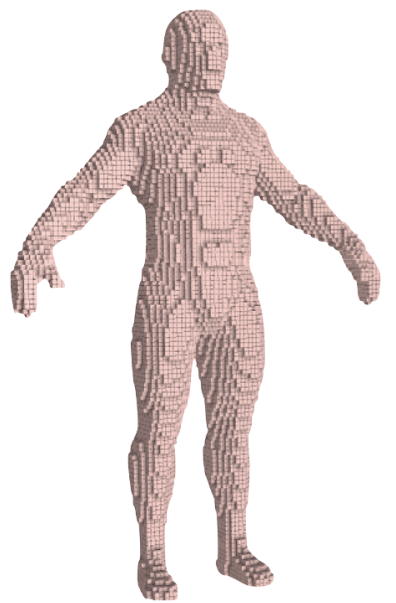

(c)

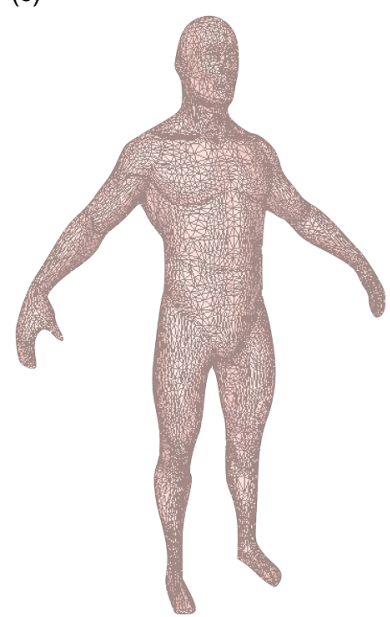

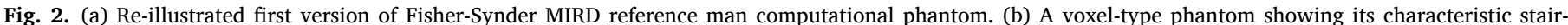
stepped surface due to being constructed of cuboids. (c) A mesh-based model defined by vertices, edges, and faces.

anatomical structures are modelled by binary segmentation of the clinical images. Using the CSG modelling technique, the resulting organ volumes are defined as an assembly of 3D cuboids. Voxel phantoms are also known as tomographic phantoms and tend to be anatomically realistic.

(c) BREP phantoms refers to phantoms defined by their surface boundaries rather than as geometric objects. Most existing BREP phantoms are either NURBS-based or mesh-based [39,40,47-51]. In NURBS-based phantoms, the surfaces are defined by NURBS equations which are represented by a set of control points. For polygonal mesh-based phantoms, the body contour and organ boundaries are described by a set of vertices, edges, and faces in 3D space. BREP phantoms are also referred to as "Hybrid" phantoms in the literature [52].

Beginning in the late 1980s, advancements in medical imaging provided huge improvements in the resolution of cross-sectional internal anatomical features captured via CT and MRI. Extensive manual segmentation of sectional images enabled the generation of detailed voxelbased anatomical features, hitherto only crudely described by simple equations [41,53-55]. Although voxel phantoms demonstrate a high specificity of anatomical detail, they are also limited by the size of the voxels; some organ structures cannot be accurately defined by a single voxel, such as skin thickness. In addition, voxel models are difficult to deform due to their nature.

BREP phantoms were introduced in the 2000s. BREP phantoms have the advantage of surface and shape deformability, where internal organs can be relatively easily modified. This allows the feasibility of fourdimensional simulation, namely organ motion such as cardiac motion and respiration [40]. Compared to voxel phantoms, BREP phantoms enable high flexibility and detailed geometries while still being relatively computationally efficient [56].

\subsection{The Monte Carlo toolkits}

Since the late 1960s, MC techniques have been used in medical physics especially in radiotherapy physics, diagnostic $\mathrm{x}$-ray, and radiation protection [57]. In general, MC toolkits are widely used in high energy physics. These toolkits can simulate neutron, photon, electron, or coupled neutron/photon/electron transport from a few kilo-electronvolts to Giga-electron-volts in heterogenous phantoms.

Several general-purpose MC toolkits widely used in diagnostic X-ray dosimetry, include MCNP (Monte Carlo N-Particle) or MCNPX (Monte Carlo N-Particle eXtended), EGSnrc (Electron Gamma Shower, National
Research Council), GEANT4 (GEometry ANd Tracking), and PENELOPE (PENetration and Energy Loss of Positrons and Electron) [58-63]. However, some significant variations in the calculated dose has been noticed when comparing different codes, especially in low energy photon ranges [64].

In general, probability distribution functions of the X-ray spectra are used as inputs in the simulations and the user defines the geometries to be simulated. The computing time required for each simulation largely depends on the number of histories (particles) to be simulated, the kind of incident particle, its initial energy, the considered geometry, etc. During their early development, most MC toolkits only supported simple geometries such as stylised and voxel phantoms. Currently, most MC toolkits can support more complex parametric models such as BREP phantoms through new solid class definitions [65-68].

\subsection{Reconstruction of the virtual clinical setting}

Reconstruction of the clinical setting is not a straightforward task. Unlike general X-ray procedures, the setup of fluoroscopic units for angiography procedures are much less standardised and consequently more complex. In interventional procedures, the patient usually lies on the examination couch, with the X-ray tube located beneath (as shown in Fig. 3). The centre of the X-ray beam is aligned to the image receptor (detector) while the projection angle usually lies within the coronal or transverse plane of the patient's body. During IR procedures, the use of oblique angles is critically important for determining the spatial

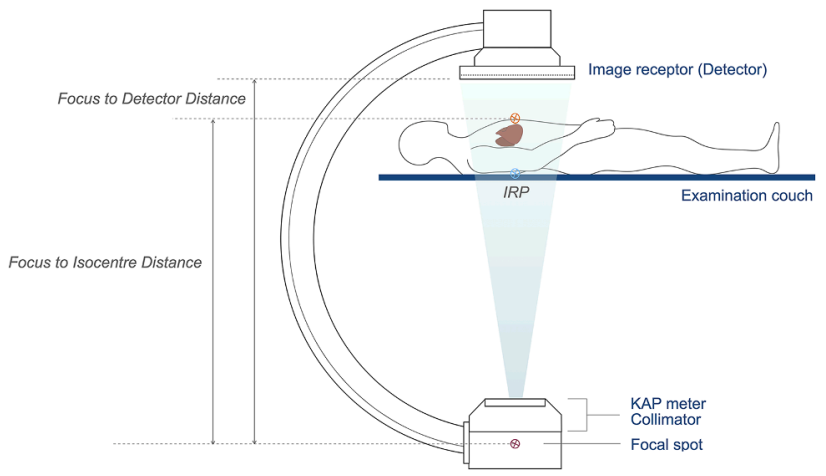

Fig. 3. The characteristic setup of the C-arm fluoroscopic X-ray tube. The IRP stands for interventional reference point, located $15 \mathrm{~cm}$ from the isocentre towards the X-ray tube, and is used as a reference point for the patient's skin entrance for the clinical procedure [20]. 
relationship of structures and procedural equipment (e.g., access needle, catheters). In addition, the focus-to-image receptor distance may also be varied.

During interventional radiology procedures, the character of the $\mathrm{X}$ ray beam penetrating the patient's body is strongly dependent on the projection angulation (beam direction and angles), the source-to-patient distance, clinical exposure parameters (tube potential, filtration, etc.), field of view (FOV) etc., as illustrated in Fig. 4. Therefore, to obtain accurate organ dose distributions of the patient, a MC simulation needs to combine the computational phantoms with detailed information of the radiation beam. In general, most machine-controlled irradiation parameters are well-recorded in the radiation dose structured report (RDSR), but other information such as precise patient positioning are usually just assumed.

\section{Results and discussion}

\subsection{Overview of Monte Carlo dose estimation methodology}

The use of MC methods in dose estimation for interventional procedures gradually increased since the 2000s (Fig. 5). In radiological imaging, MC methods were initially implemented for general radiography procedures; various MC simulation applications were developed for general radiography patient dose estimation particularly during the period of 1980 to 1990s. These applications were then later adapted for use in interventional procedures. Although fluoroscopy and radiography both utilise X-rays of similar energies, the dynamic nature of fluoroscopy procedures does pose a challenge to model compared to the relatively static procedures in general radiography, especially for continuously changing FOVs and exposure parameters such as tube angulation.

Table 2 lists seven MC-based applications, most of which were developed in the 1990s. All of them were originally designed for dose estimation in general X-ray projection radiography. Most published papers utilising these applications for fluoroscopy, used them as an estimation tool without any modification. Limited number of papers proposed new ideas as add-ons, such as phantom-beam alignment [69]. In addition, there are a smaller proportion of research groups (24 publications) that developed their own customised MC simulation scenarios using general MC physics toolkits such as GEANT4, to address special research needs and focuses.

\subsubsection{Methodological issues in existing Monte Carlo-based applications.}

Studying the MC-based applications shown in Table 2, applications up to the early 2000s all utilised simple geometries to define the human body contour and organ structures, as they require the least amount of computational resources. However, such stylised phantoms are very limited in their representation of anatomical structures, which can lead to high levels of error in patient dose estimation [77,78].

As mentioned in Section 4.3, the calculated dose is also largely dependent on patient positioning, such as the table position and tube angulation. Unfortunately, these software struggle to reflect the complexity of current clinical circumstances, as their built-in simulations usually have limited functionality, such as being limited to single radiographic projections without the consideration of fluoroscopy time for irradiation events within each procedure. Also, some important IR clinical parameters were not accounted in their dose estimation, such as the attenuation of the examination couch etc.

\subsubsection{Overview of customised Monte Carlo studies}

Table 3 lists publications that estimated IR organ dose through customised MC simulations. The majority of the studies implemented more advanced BREP-based anatomical models in their simulations, and more extensively virtualised the clinical environment by accounting for important influence quantities such as table attenuation for photon transmission. The reason for the emphasis on table attenuation here, is that it represents a relatively straightforward addition for improved simulation accuracy. The lack of table attenuation in the simulation would also theoretically underestimate the scatter contribution, which may cause dosimetric inaccuracies particularly for patients with larger sizes.

\subsection{Challenges in virtual model reconstruction}

Two current challenges contribute to the uncertainties in virtual simulation reconstruction: firstly, the patient-phantom matching or creation/selection of a phantom which precisely describes an individual patient, and secondly the phantom-patient or phantom-beam alignment which accurately matches the position and orientation of the patient on the examination couch relative to the actual X-ray beam during the simulated clinical procedures. This section gathers the techniques which have been developed to overcome these challenges.

\subsubsection{Patient-phantom matching}

The accuracy of a given MC simulation highly depends on the accuracy of its computational model reflecting the real-world clinical scenario. The term patient-phantom matching refers to the selection of anatomical models based on anthropometric measurements of the individual patients of interest [98]. The matching techniques match the computational models to the anthropometric characteristics of a patient, starting with general characteristics such as gender, age, height, and weight, and also extending to detailed anatomical features such as body contour and internal organ shape.
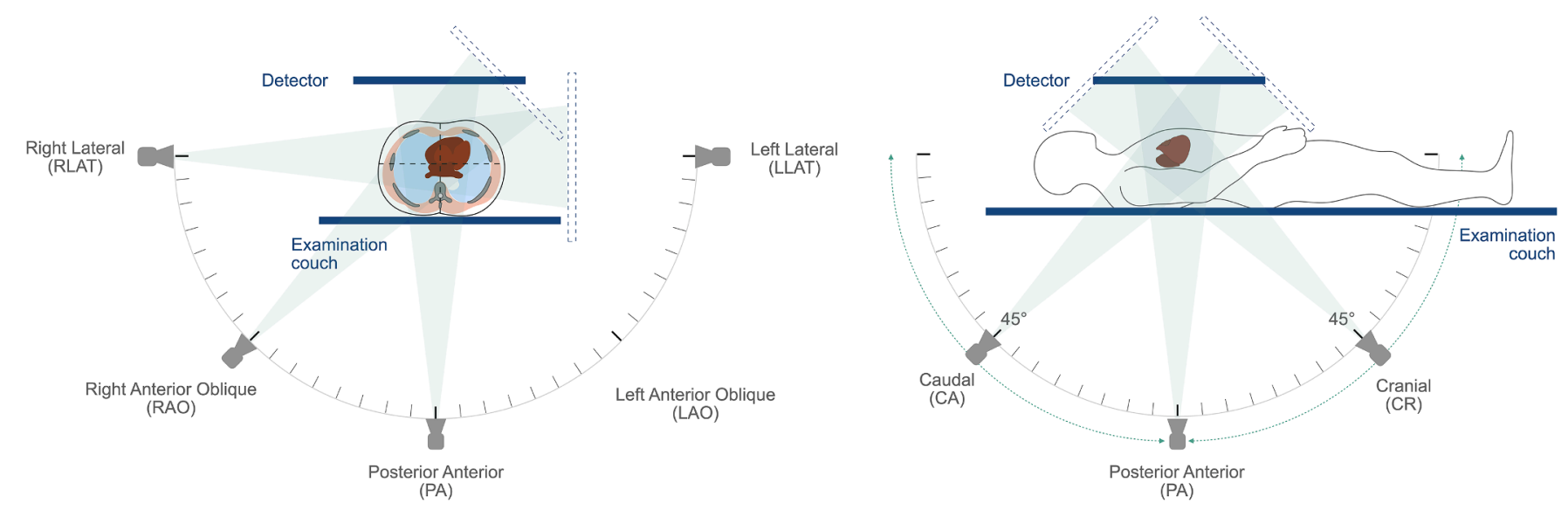

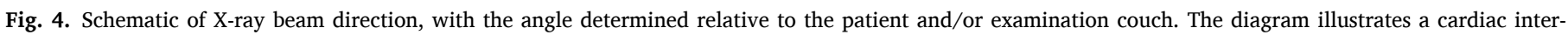
ventional procedure. 


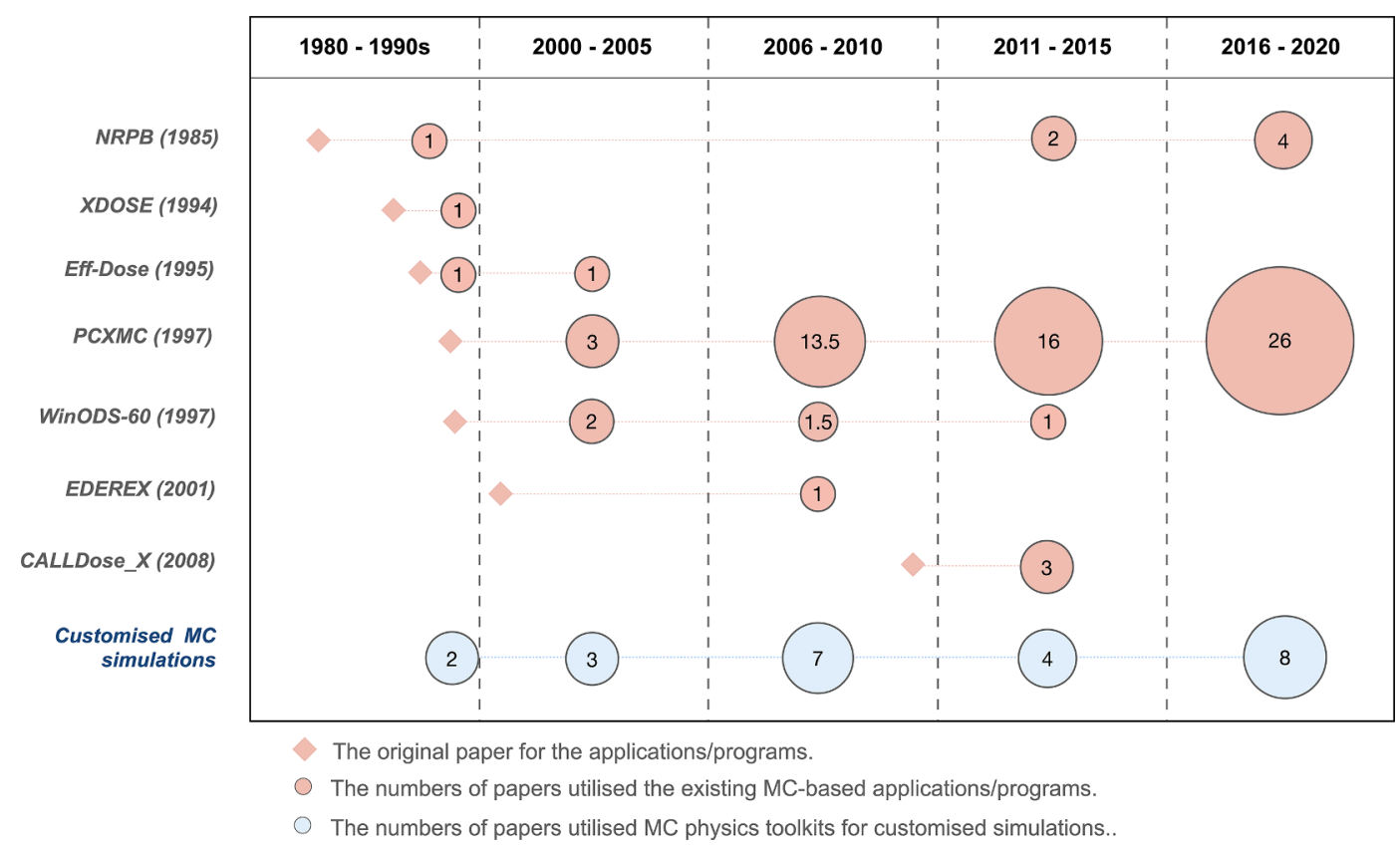

Fig. 5. Chronological distribution of 101 reviewed publications utilising MC methods, either through existing MC-based application/program or through customised MC simulations. Each circle is proportional to the number of papers.

Table 2

Existing MC-based applications for diagnostic imaging radiation physics.

\begin{tabular}{|c|c|c|c|}
\hline $\begin{array}{l}\text { Identified } \\
\text { Application }\end{array}$ & Institutions & $\begin{array}{l}\text { Phantom } \\
\text { Classification }\end{array}$ & Phantom Name \\
\hline $\begin{array}{l}\text { (a) NRPB, } 1985 \\
\text { [70] }\end{array}$ & $\begin{array}{l}\text { UK National } \\
\text { Radiological Protection } \\
\text { Board, now subsumed } \\
\text { within Public Health } \\
\text { Protection, England. }\end{array}$ & Stylised & $\begin{array}{l}\text { Fisher-Synder } \\
\text { (MIRD-5) }\end{array}$ \\
\hline $\begin{array}{l}\text { (b) XDOSE, } \\
1994[71]\end{array}$ & $\begin{array}{l}\text { National Radiation } \\
\text { Laboratory, Ministry of } \\
\text { Health, Christchurch, } \\
\text { New Zealand. }\end{array}$ & Stylised & $\begin{array}{l}\text { Cristy-Eckerman } \\
\text { Family phantom }\end{array}$ \\
\hline $\begin{array}{l}\text { (c) Eff-Dose, } \\
1995[72]\end{array}$ & $\begin{array}{l}\text { National Board of } \\
\text { Health, Denmark: } \\
\text { National Institute of } \\
\text { Radiation Hygiene. }\end{array}$ & Stylised & $\begin{array}{l}\text { Cristy-Eckerman } \\
\text { Family phantom }\end{array}$ \\
\hline $\begin{array}{l}\text { (d) PCXMC, } \\
1997[73]\end{array}$ & $\begin{array}{l}\text { STUK, the Finnish } \\
\text { Radiation Protection } \\
\text { Authority, Finland. }\end{array}$ & Stylised & $\begin{array}{l}\text { Cristy-Eckerman } \\
\text { Family phantom }\end{array}$ \\
\hline $\begin{array}{l}\text { (e) WinODS- } \\
60,1997 \\
{[74]}\end{array}$ & $\begin{array}{l}\text { RTI Electronics AB, } \\
\text { Mölndal, Sweden. }\end{array}$ & Stylised & $\begin{array}{l}\text { Computational } \\
\text { Alderson-Rando }\end{array}$ \\
\hline $\begin{array}{l}\text { (f) EDEREX, } \\
2001 \text { [75] }\end{array}$ & $\begin{array}{l}\text { Institute of Radiation } \\
\text { Hygiene, St. } \\
\text { Petersburg, Russian } \\
\text { Federation. }\end{array}$ & Stylised & $\begin{array}{l}\text { Fisher-Synder } \\
\text { (MIRD-5), ADAM } \\
\text { and EVA }\end{array}$ \\
\hline $\begin{array}{l}\text { (g) } \\
\text { CALLDose_X, } \\
2008[76]\end{array}$ & $\begin{array}{l}\text { Department of Nuclear } \\
\text { Energy, Federal } \\
\text { University of } \\
\text { Pernambuco, Recife, } \\
\text { Brazil. }\end{array}$ & Voxel & MAX06 and FAX06 \\
\hline
\end{tabular}

The existing literature regarding patient-phantom matching in interventional radiological dosimetry is tabulated in Table 4. Chronologically, the concepts implemented for patient-phantom matching can be classified as:

a. Single Reference Man - where matching is only based on age group and gender. The computational phantom is generally created using the 50th percentile of patient height, weight, and organ mass. This concept was widely used in the early generation of MC-based applications as shown in Table 2. Generally, it lacks patient specificity. In practice, the characteristics of most patients will deviate from 50th percentile values and the variance in anatomical features of an individual cannot be well represented by a single model. Since then, different concepts ((b), (c), (d), and (e)) arose to tackle the issue of anthropomorphic variability.

b. Patient Dependent - where a patient's data is matched to a computational phantom from a predefined phantom library using height and weight. The implication is for a library of phantoms representing the diverse body shapes and contours of the population to be created. These are often created through manual remodelling of a reference phantom [98]. By this, a patient can be matched to a corresponding model that more closely resembles the patient in terms of gross body size.

c. Extended Patient Dependent Reference Library - is an extended version of the patient-dependent concept. The phantom library is extended to reflect a wider coverage of ages and weight percentiles or body mass indexes (BMI). This extension usually targets underweight, healthy, over-weight, obese and morbidly obese categories. For example, UF/NCI's phantom library modelled each height/ weight combination to match the average values of body circumference from the morphometric data of the Centre for Health Disease Control and Prevention (CDC) [103].

d. Patient-Sculpted - refers to a dynamic reshaping of the outer body contour of a selected anatomical model from the patient-dependent library, to uniquely match the individual patient. The initial selection of the anatomical model is usually based on exterior body size (BMI or body circumference) [98]. The reshaping process only applies to the body contour without any adjustments to the model's height, and subsequently remodels the subcutaneous fat and body region distribution of the model [98]. The internal organs remain unchanged in terms of location, size, and shapes. However, the internal organ volumes can be scaled accordingly when the height is adjusted.

e. Patient-Specific - where the phantom is generated according to the patient morphometry. In other words, a unique phantom is created 
Table 3

. Papers describing computational phantoms and MC toolkits that have been used to simulate IR procedures ( $\mathrm{n}=24$ ).

\begin{tabular}{|c|c|c|c|c|c|}
\hline $\begin{array}{l}\text { Phantom } \\
\text { classification }\end{array}$ & Identified phantoms & $\begin{array}{l}\text { Monte Carlo } \\
\text { toolkit }\end{array}$ & Authors & $\begin{array}{l}\text { Simulation with examination } \\
\text { couch }\end{array}$ & Stimulated procedures \\
\hline \multirow[t]{10}{*}{ Stylised } & \multirow[t]{6}{*}{$\begin{array}{l}\text { ORNL series and/or revised version } \\
\text { [79] }\end{array}$} & MCNPX & $\begin{array}{l}\text { Karimian et al., } 2014 \\
{[80]}\end{array}$ & * & Renal angiography \\
\hline & & MCNP & Smans et al., 2008 [81] & * & Lower limbs angiography \\
\hline & & MCNP & $\begin{array}{l}\text { Stratakis et al., } 2007 \\
{[82]}\end{array}$ & $*$ & Percutaneous transhepatic biliary \\
\hline & & MCNP & $\begin{array}{l}\text { Stratakis et al., } 2006 \\
\text { [83] }\end{array}$ & * & $\begin{array}{l}\text { Percutaneous transluminal } \\
\text { angioplasty }\end{array}$ \\
\hline & & MCNP & Bacher et al., 2005 [84] & $\mathrm{Y}$ & Cardiac catherisation \\
\hline & & MCNP & $\begin{array}{l}\text { Van De Putte et al., } 2000 \\
\text { [85] }\end{array}$ & $\mathrm{Y}$ & Cardiac interventions \\
\hline & \multirow{4}{*}{$\begin{array}{l}\text { ADAM and/or EVA, or modified } \\
\text { version [86] }\end{array}$} & MCNP & Vetter et al., 2004 [87] & $*$ & Uterine artery embolisation \\
\hline & & MCNP & Schultz et al., 2003 [88] & $\mathrm{Y}$ & Cardiac catherisation \\
\hline & & MCNP & $\begin{array}{l}\text { Kemerink et al., } 1999 \\
\text { [89] }\end{array}$ & * & Abdominal arteriography \\
\hline & & $*$ & Kicken et al., 1999 [90] & $\mathrm{Y}$ & Peripheral arteriography \\
\hline \multirow[t]{4}{*}{ Voxel } & VIP-Man [91] & MCNP & Bozkurt et al., 2006 [92] & $\mathrm{Y}$ & Cardiac interventions \\
\hline & KTMAN-2 [43] & MCNPX & Park et al., 2008 [93] & $*$ & Cardiac catherisation \\
\hline & Frank, Golem, and Visible Human & GEANT4 & Roser et al., 2019a [96] & * & Non-specific IR procedures \\
\hline & {$[94,95]$} & GEANT4 & Roser et al., 2019b [14] & $\mathrm{Y}$ & Non-specific IR procedures \\
\hline \multirow[t]{10}{*}{ BREP } & \multirow[t]{2}{*}{ UF phantoms [97] } & MCNPX & $\begin{array}{l}\text { Johnson et al., } 2011 \\
{[98]}\end{array}$ & $\mathrm{N}$ & $\begin{array}{l}\text { Abdominal and cardiac IR } \\
\text { procedures }\end{array}$ \\
\hline & & MCNPX & $\begin{array}{l}\text { Johnson et al., } 2009 \\
\text { [99] }\end{array}$ & $\mathrm{N}$ & Cardiac catherisation \\
\hline & \multirow[t]{2}{*}{$\begin{array}{l}\text { FASH, and/or MASH or modified } \\
\text { version [100] }\end{array}$} & EGSnrc & $\begin{array}{l}\text { Garzon et al., } 2015 \\
{[101]}\end{array}$ & $*$ & Hepatic chemoembolisation \\
\hline & & MCNP & Santos et al., 2015 [102] & $\mathrm{Y}$ & Cardiac catherisation \\
\hline & \multirow[t]{3}{*}{ UF/NCI phantoms [103] } & MCNPX & $\begin{array}{l}\text { Borrego et al., } 2017 \\
\text { [104] }\end{array}$ & $\mathrm{Y}$ & Non-specific IR procedures \\
\hline & & MCNPX & $\begin{array}{l}\text { Marshall et al., 2018a } \\
\text { [105] }\end{array}$ & $\mathrm{Y}$ & Cardiac catherisation \\
\hline & & MCNPX & $\begin{array}{l}\text { Marshall et al., 2018b } \\
{[52]}\end{array}$ & $\mathrm{Y}$ & Cardiac catherisation \\
\hline & In-house mesh-based phantom & MCNPX & Huet et al., 2019 [106] & $\mathrm{N}$ & Non-specific IR procedures \\
\hline & \multirow[t]{2}{*}{ library } & MCNPX & Huo et al., 2019 [107] & $\mathrm{N}$ & Non-specific IR procedures \\
\hline & & MCNPX & Huo et al., 2017 [108] & $\mathrm{N}$ & Non-specific IR procedures \\
\hline
\end{tabular}

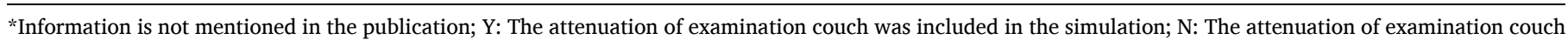
was excluded from simulation.

from the segmentation of the patient's own clinical radiological images. Depending on the segmentation's degree of detail, the phantom will be a nearly exact match to the individual patient, potentially cloning anatomical features such as internal organ size, depth, and shape.

5.2.1.1. Performance of current approaches. Regardless of the type of phantom and matching technique, dosimetry errors arise due to discrepancies between the reconstruction of the experimental setup and the anatomical assumptions of the patient. Objective comparison between approaches is challenging due to the many variables involved, (i.e., exposure parameters, type of procedures, etc.) and the various metrics used for evaluating the dose differences. Only a few publications compared patient-phantom matching methodologies.

As presented in Table 5, moving from stylised to BREP phantoms showed improvements of 33 to $42 \%$. However, moving from single reference BREP to patient dependent libraries showed smaller improvements of approximately $7-10 \%$. Given that BREP phantom libraries are primarily targeted against outer body contours, this suggests that the remaining errors are dominated by other factors such as patientinternal features. Using the patient-specific model as a reference standard, there is approximately $38-42 \%$ space for improvement in future developments.

Another observation is that the percentage dosimetry error increases on organs located further from the irradiated regions, e.g., 74 to $85 \%$ difference for the bladder for a projection centred on the stomach. Having said that, these large percentage differences also coincide with generally small absolute dose differences.

The current state of the art phantom libraries try to account for gender, age group, and body mass/size [52]. The issue of anthropomorphic variations may improve by expanding the library to include more physical characteristics. However, this may not be practical as the combinatorial complexity of additional features may result in impractically large phantom libraries. Indeed, it suggests that future improvements may lie with phantoms that can be modified to suit the individual patient, including for patient-internal features such as organ structure.

5.2.1.2. Population-based and patient-specific approaches. An alternate grouping is for phantom morphometric techniques to be classified into two approaches, either population-based or patient-specific. The population-based approach refers to the use of anatomical models based on averaged or clustered population data, while the patient-specific approach refers to anatomical models based on an individual's morphology and clinical circumstances.

Current research for IR patient organ dosimetry largely focuses on population-based approaches in patient-phantom matching. Unfortunately, as mentioned in Section 5.2.1.1, population-based approaches suffer from uncertainties in internal organ shape and location, which contributes to high prediction errors in organ dose estimation. Patientspecific approaches have the potential to overcome these issues, but in current practice they are highly dependent on (1) the need for tomographic images with sufficient resolution and scan coverage, and (2) organ segmentation of these clinical images. These can be summarised as the lack of volumetric detail in IR images, and the limits of 
Table 4

Patient-phantom matching techniques used for MC simulation.

\begin{tabular}{|c|c|c|c|}
\hline $\begin{array}{l}\text { Patient- } \\
\text { phantom } \\
\text { matching } \\
\text { concepts }\end{array}$ & $\begin{array}{l}\text { Matching } \\
\text { methodology }\end{array}$ & $\begin{array}{l}\text { Type of } \\
\text { anatomical } \\
\text { model }\end{array}$ & Authors \\
\hline $\begin{array}{l}\text { Single } \\
\text { Reference } \\
\text { Man }\end{array}$ & Gender and age & Stylised & $\begin{array}{l}\text { Karimian et al., } 2014 \\
\text { [80] } \\
\text { Smans et al., } 2008 \text { [81] } \\
\text { Stratakis et al., } 2007 \\
\text { [82] } \\
\text { Stratakis et al., } 2006 \\
\text { [83] } \\
\text { Bacher et al., } 2005 \text { [84] } \\
\text { Vetter et al., } 2004 \text { [87] } \\
\text { Schultz et al., } 2003 \text { [88] } \\
\text { Van De Putte et al., 2000 } \\
\text { [85] } \\
\text { Kemerink et al., } 1999 \\
\text { [89] } \\
\text { Kicken et al., 1999 [90], } \\
\text { and includes the MC- } \\
\text { based applications } \\
\text { mentioned in Table } 2 \text { (a- } \\
\text { f). }\end{array}$ \\
\hline & & Voxel & $\begin{array}{l}\text { Roser et al., 2019a [96] } \\
\text { Roser et al., 2019b [14] } \\
\text { Park et al., 2008 [93] } \\
\text { Bozkurt et al., 2007 } \\
\text { [92], and MC-based } \\
\text { applications mentioned } \\
\text { in Table } 2 \text { (g). }\end{array}$ \\
\hline & & BREP & $\begin{array}{l}\text { Marshall et al., 2018b } \\
\text { [52] } \\
\text { Santos et al., } 2015 \text { [102] }\end{array}$ \\
\hline $\begin{array}{l}\text { Patient } \\
\text { Dependent } \\
\text { and Library }\end{array}$ & $\begin{array}{l}\text { Nearest height / } \\
\text { weight }\end{array}$ & BREP & $\begin{array}{l}\text { Marshall et al., 2018a } \\
\text { [105] } \\
\text { Borrego et al., } 2017 \\
\text { [104] } \\
\text { Garzon et al., } 2015 \\
\text { [101] } \\
\text { Johnson et al., 2011a } \\
\text { [98] } \\
\text { Johnson et al., } 2009 \\
\text { [99] }\end{array}$ \\
\hline $\begin{array}{l}\text { Extended } \\
\text { Patient } \\
\text { Dependent } \\
\text { and Library }\end{array}$ & $\begin{array}{l}\text { Height, weight } \\
\text { and body } \\
\text { circumference }\end{array}$ & BREP & $\begin{array}{l}\text { Huo et al., } 2019 \text { [107] } \\
\text { Marshall et al., 2018b } \\
\text { [52] } \\
\text { Huo et al., } 2017 \text { [108] }\end{array}$ \\
\hline $\begin{array}{l}\text { Patient } \\
\text { Sculpted }\end{array}$ & $\begin{array}{l}\text { Height, weight } \\
\text { and body contour }\end{array}$ & BREP & $\begin{array}{l}\text { Johnson et al. (2011a) } \\
\text { [98] }\end{array}$ \\
\hline Patient Specific & $\begin{array}{l}\text { Uniquely match } \\
\text { patient's } \\
\text { morphology }\end{array}$ & $\begin{array}{l}\text { Voxel } \\
\text { BREP } \\
\text { Voxel }\end{array}$ & $\begin{array}{l}\text { Huet et al., } 2019 \text { [106] } \\
\text { Marshall et al., } 2018 b \\
\text { [52] } \\
\text { Johnson et al. 2011a } \\
\text { [98] }\end{array}$ \\
\hline
\end{tabular}

computational power.

A related approach is the concept of deformable anatomical phantoms; this consists of geometrically deforming one shape to another, and usually involves surface geometries such as NURBS and polygonal meshes. Several research groups have demonstrated the feasibility of creating deformable BREP phantoms. However, to date the scope is limited to (1) "pre-clinical" alteration of a generic anatomical phantom to create varying anatomical models to populate a phantom library, (2) creation of deformable outer body contour to match individual patients $[109,110]$.

Given the flexibility and extensibility of deformable anatomical phantoms, they present a potential alternative approach to building patient-specific models [111-114]. Rather than building a model from segmented tomographic volumes, phantoms with deformable internal organs might be capable of being moulded to match individual organ location and shape solely based on IR projection images. Since projection images do not contain information on thickness and depth, such models could not be considered totally patient specific. However, it is still likely that it would represent a significant improvement in dosimetry accuracy.

\subsubsection{Patient-phantom and phantom-beam alignment}

In multi-slice modalities such as CT, the patient's orientation is usually well aligned to the scanner; the patient's isocentre is identified via scout views and their subsequent positioning is aided by axial, coronal and sagittal alignment. In general radiography, procedures are static and usually only require a limited number of projections or views. In contrast, interventional procedures are generally more complicated; routine procedures utilise a series of projections to observe contrast dye passing through patient's arteries and veins. The FOV can be varied for the same type of procedure, as it is highly dependent on the arterial access site.

Patient-phantom alignment describes the positioning of the virtual model with respect to the actual patient in the clinical setting, as defined in a common coordinate space. In most papers, the virtual model's positioning in the MC simulation is based on a fixed standard location; the vast majority assumed that the patient is located at the centre of the examination couch, with a fixed distance from the edge (head end of the examination couch).

Phantom-beam alignment describes the positioning of the virtual model relative to the X-ray tube, so that $\mathrm{x}$-ray field can be accurately projected onto the virtual model as per the actual clinical scenario. For modern fluoroscopy systems, scenario-specific information such as the distance between the X-ray tube to examination couch and the tube angle relative to examination couch, can be retrieved from the RDSR. However, the precise orientation and positioning of the patient during examination is largely unknown.

These alignment issues are commonly discussed in papers on skin dose mapping $[28,29]$, however, they has not received enough attention in the literature for MC-based systems developed for internal organ dose in interventional procedures. Only two publications proposed new alignment approaches:

(a) Head-centric refers to a technique with an assumption that the patient's head is initially located at a manually measured distance from the head end of the examination couch (illustrated in Fig. 6(a)), as proposed by Omar et al. (2016) [69]. The same concept was labelled as the "Table alignment" method by Marshall et al. (2018a) [105].

(b) Target-centric refers to a technique where the specific coordinates of the target organ (usually the mid-point of the organ) are measured and used as the reference point, as defined by Omar et al. (2016) [69]. The same concept was labelled as "Geometric centre alignment" as Marshall et al. (2018a) [105]. The main motivation of this technique is for procedures that are organcentred such as cardiac catheterisation. The centre of the organ is used as the reference point to align with the isocentre of the beam in the MC coordinate system (as illustrated in Fig. 6(b)). This approach has demonstrated better agreement in alignment compared to the head-centric approach [69].

(c) Image-based reference alignment refers to a ground truth method where one or more landmarks in the clinical images (both anterior-posterior and lateral views) are manually located, matched with corresponding landmarks in the computational phantom, which enables accurate alignment of the phantom to the isocentre of the X-ray beam in the MC system [105].

The uncertainties in the actual patient's orientation and position can introduce misalignment between the phantom to the X-ray beam and subsequently cause large discrepancies in organ dose estimation. Both studies demonstrated that the target-centric approach improves the accuracy of alignment for cardiovascular procedures, where the heart is used as the target organ. Though the target-organ is well matched, 
Table 5

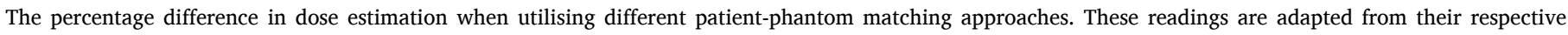
publications.

\begin{tabular}{|c|c|c|c|c|c|c|}
\hline \multirow{3}{*}{ Organs } & \multicolumn{6}{|l|}{ Percentage difference (\%) } \\
\hline & \multirow{2}{*}{$\begin{array}{l}\text { aPatient specific vs Patient } \\
\text { dependent and library [98] }\end{array}$} & \multirow{2}{*}{$\begin{array}{l}{ }^{\text {a }} \text { Patient specific vs Single } \\
\text { reference BREP [98] }\end{array}$} & \multirow{2}{*}{$\begin{array}{l}{ }^{\text {a}} \text { Patient specific vs Single } \\
\text { reference stylised [98] }\end{array}$} & \multicolumn{3}{|c|}{${ }^{\mathrm{b}}$ Single reference voxel vs Single reference stylised [93] } \\
\hline & & & & RAO & LAO & PA \\
\hline Esophagus & - & - & - & 55 to $61 \%$ & 0 to $13 \%$ & 18 to $27 \%$ \\
\hline Lung & 38.2 to $40.8 \%$ & 36.2 to $41.0 \%$ & 52.8 to $55.9 \%$ & 12 to $34 \%$ & 46 to $52 \%$ & 60 to $62 \%$ \\
\hline Pericardium/Heart & 41.5 to $43.7 \%$ & 36.2 to $39.4 \%$ & 74.1 to $76.5 \%$ & * - & $*$ & $*$ \\
\hline Stomach & $* 28.0$ to $32.0 \%$ & $* 32.0$ to $36.9 \%$ & $* 46.6$ to $56.6 \%$ & 72 to $75 \%$ & 68 to $75 \%$ & 64 to $73 \%$ \\
\hline Pancreas & 24.6 to $25.2 \%$ & 30.1 to $32.6 \%$ & 26.7 to $32.7 \%$ & - & - & - \\
\hline Liver & 26.8 to $29.2 \%$ & 45.5 to $51.8 \%$ & 46.5 to $46.7 \%$ & 55 to $63 \%$ & 46 to $52 \%$ & 60 to $62 \%$ \\
\hline Spleen & 20.3 to $23.5 \%$ & 28.6 to $34.3 \%$ & 42.5 to $52 \%$ & - & - & - \\
\hline Kidney & 45.9 to $52.8 \%$ & 66.1 to $73.8 \%$ & 151.9 to $186.6 \%$ & - & - & - \\
\hline Bladder & 74.3 to $85.1 \%$ & 83.3 to $98.9 \%$ & 172.4 to $240.1 \%$ & - & - & - \\
\hline${ }^{\mathrm{c}}$ Average & 37.5 to $41.6 \%$ & 44.2 to $51.1 \%$ & 76.7 to $93.3 \%$ & - & - & - \\
\hline
\end{tabular}

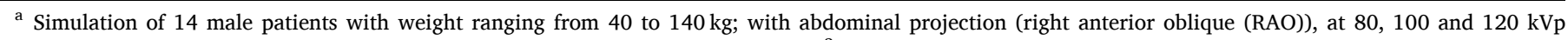
respectively. The projections were centred at the stomach, with FOV $=11.5 \times 11.5 \mathrm{~cm}^{2}$, and source-to-skin distance fixed at $50 \mathrm{~cm}$.

b Simulation done at $60 \mathrm{kVp}$ to $120 \mathrm{kVp}$, FOV at centre of heart $=12 \times 12 \mathrm{~cm}^{2}$.

c The average difference across all organs.

* The centre of projection.

greater misalignment can be observed for organs located further from the target organ (e.g., the breast and liver) in both approaches (as illustrated in Table 6).

Although the alignment accuracy improved when using the targetcentric approach, the technique is still made with an assumption that the target organ always remains at the centre of the FOV. I.e., the target organ coordinate measurement is only made once. However, this may not be the case in clinical practice. The dynamic nature of interventional procedures encompasses continuously changing FOVs and patient repositioning in order to direct the beam towards targeted arteries. In certain procedures such as hepatic artery angiography, the celiac artery and arterial branches to the liver determine the target FOV, instead of the liver itself. As such, the target-centric approach is unlikely to be useful for such procedures.

\subsection{Dose conversion coefficients (DCCs)}

In the previous sections, the assumption is for a full MC simulation to be run for each individual patient. An alternative approach is to estimate patient dose through dose conversion coefficients (DCCs). DCCs are defined as the ratio of a radiation risk quantity (such as effective dose) to a measurable indirect radiation quantity (e.g., KAP). In order to determine the dose conversion coefficients, MC simulation is usually performed to evaluate the organ doses for a specified clinical scenario and computational phantom pairing.

However, estimation of patient dose through DCCs is not straightforward, as DCCs are usually only derived for a limited number of specific procedures. Differences in clinical setting such as beam angle, projection view, FOV, beam quality, exposure parameters, the use of filtration, etc., can lead to discrepancies in DCCs which could subsequently cause a high percentage of error in dose estimation [81,102]. Other factors such as disagreement on patient-phantom matching and beam alignment as mentioned in Sections 5.2.1 and 5.2.2 are also present and contribute to high relative error, as DCCs are sensitive to anthropometric changes especially the subcutaneous fats located superficial to major target organs $[77,99]$. Discrepancies in the projection view can also cause errors, e.g., lateral projection can be 1.6 times higher than anterior-posterior (AP) view [115].

\section{Conclusion and perspective}

For virtual simulation to accurately reflect clinical procedures requires two essential parameters: (1) the anatomical model precisely representing the patient, and (2) accurate reconstruction of the virtual $\mathrm{X}$-ray beam and anatomical model alignment.

The first challenge involves the use of anatomical models to accurately represent the characteristic of an individual. The introduction of phantom libraries attempts to balance the needs of clinical practicality with those of specificity. However, the dosimetric response to radiation exposure depends more on the location and shape of the organ rather than on the organ volume [43]. Mismatch of anatomical variation in body size and organ shape can create large discrepancies in dose estimations $[43,95]$. The common use of BMI and body circumference to match a specific individual with a library of reference phantoms, is mainly for retrospective patient dose tracking and accidental dose reconstruction [116]. It might help in skin dose estimations but is

Table 6

Comparison of dosimetry accuracy between head- and target-centric approaches. For comparison, we adapted the data for paediatric cardiovascular procedures from both papers. The dose differences between each approach were assessed against simulations utilising image-based ground truth. Positive values denote overestimation, and negative values denote under-estimation of organ doses.

\begin{tabular}{|c|c|c|c|c|}
\hline \multirow[b]{3}{*}{ Percentage of Difference (\%) } & \multicolumn{2}{|c|}{ Omar et al., 2016 [69] } & \multicolumn{2}{|c|}{ Marshall et al., 2018a [105] } \\
\hline & Head-Centric & Target-Centric & Head-Centric & Target-Centric \\
\hline & Max & Max & Range ofdifference & Range of difference \\
\hline Breast & $-83.0 \%$ & $14.0 \%$ & -94.2 to $74.9 \%$ & -55.0 to $330.7 \%$ \\
\hline Esophagus & $-43.1 \%$ & $-1.1 \%$ & -36.0 to $13.6 \%$ & 0.0 to $41.1 \%$ \\
\hline Lung & $-55.4 \%$ & $-4.1 \%$ & -80.2 to $0.2 \%$ & 9.5 to $41.1 \%$ \\
\hline *Heart & $-63.7 \%$ & $2.9 \%$ & -86.4 to $-0.8 \%$ & 7.8 to $20.9 \%$ \\
\hline Stomach & $16.5 \%$ & $3.5 \%$ & -80.4 to $88.2 \%$ & -67.4 to $-43.9 \%$ \\
\hline Liver & $22.1 \%$ & $-3.9 \%$ & -84.0 to $73.5 \%$ & -73.2 to $-30.4 \%$ \\
\hline
\end{tabular}

* Target organ. 
(a)

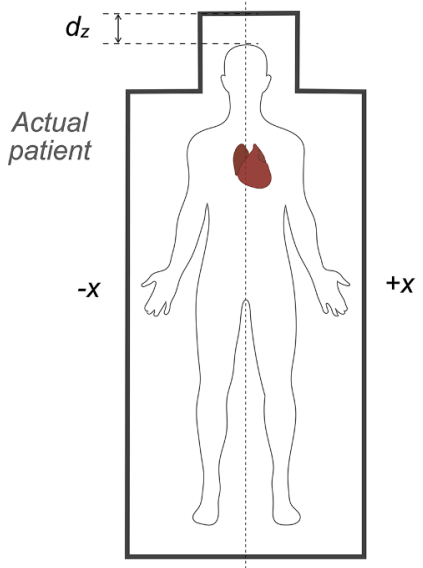

(b)
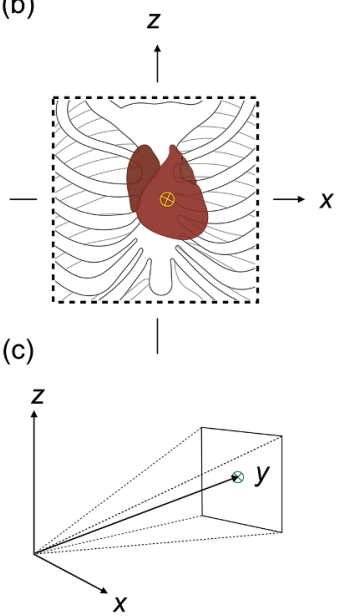

Fig. 6. Schematic illustration of patient-phantom and phantom-beam alignment techniques. (a) For the head-centric technique, the distance between the examination couch head-end to the patient's head $\left(\mathrm{d}_{\mathrm{z}}\right)$ is used as a reference coordinate to align the virtual models in the MC system. For the target-centric technique, the target organ mid-point (e.g., heart) of the computational phantom is used as the reference point, to align with the X-ray beam isocentre in the MC code, represented by the y-coordinate in (c).

unlikely to be accurate for internal organ dosimetry. Dynamic, deformable phantoms help to improve patient specificity, but at present are only limited to adjustment of gross body volume. Dynamic internal organ displacement or reshaping is likely the next logical frontier.

The second challenge reflects the issues that the exact positioning of the patient on the examination couch is generally unknown. Most dose prediction models only assume that the patient is located centrally on the examination couch, which leads to significant errors. The alternative target-centric approach is not likely to be a general solution, as it is only limited to highly organ-centric procedures such as cardiac interventions. Image-based alignment is likely the most promising solution, but it has to be automated to be clinically practical.

Finally, the increase in computing power has improved the efficiency of MC simulation, especially GPU-based MC which has demonstrated faster results as compared to conventional MC studies [13]. In addition, deep learning (DL) has had a tremendous impact on medical image processing. The integration of GPU-accelerated MC simulation with DL may help to solve some of the current issues limiting practical clinical usage, such as (i) enabling faster simulation via DL function approximation, and (ii) enabling automated deformation modelling, etc. [14]. Such improvements may lead to practical real-time internal organ dosimetry for interventional radiology.

\section{Declaration of Competing Interest}

The authors declare that they have no known competing financial interests or personal relationships that could have appeared to influence the work reported in this paper.

\section{Acknowledgements}

This study is supported by the Fundamental Research Grant Scheme (FRGS) (FRGS/1/2020/SKK0/UM/02/30) under the Ministry of Higher Education Malaysia.

The authors gratefully acknowledge Associate Professor Dr. Kiang Hiong, Tay (Department of Vascular and Interventional Radiology, Singapore General Hospital) and Dr. Poh Choo, Seow (Division of Radiological Sciences, Singapore General Hospital) for their valuable inputs and contributions.

\section{Appendix A. Supplementary data}

Supplementary data to this article can be found online at https://doi. org/10.1016/j.ejmp.2021.03.004.

\section{References}

[1] Carstens G, Horowitz M, Purdy P, Pandya A. Radiation dermatitis after spinal arteriovenous malformation embolization: case report. Neuroradiology 1996;38: S160-4. https://doi.org/10.1007/bf02278147.

[2] Koenig TR, Mettler FA, Wagner LK. Skin injuries from fluoroscopically guided procedures: part 2, review of 73 cases and recommendations for minimizing dose delivered to patient. Am. J. Roentgenol. 2001;177:13-20. https://doi.org/ 10.2214/ajr.177.1.1770013.

[3] Koenig TR, Wolff D, Mettler FA, Wagner LK. Skin injuries from fluoroscopically guided procedures: part 1, characteristics of radiation injury. Am. J. Roentgenol. 2001;177:3-11. https://doi.org/10.2214/ajr.177.1.1770003.

[4] Shope TB. Radiation-induced skin injuries from fluoroscopy. Radiographics 1996; 16:1195-9. https://doi.org/10.1148/radiographics.16.5.8888398.

[5] Wagner LK, Eifel PJ, Geise RA. Potential biological effects following high X-ray dose interventional procedures. J Vasc Interv Radiol. 1994;5:71-84. https://doi. org/10.1016/s1051-0443(94)71456-1.

[6] Wagner LK, McNeese MD, Marx MV, Siegel EL. Severe skin reactions from interventional fluoroscopy: case report and review of the literature. Radiology 1999:213:773-6. https://doi.org/10.1148/radiology.213.3.r99dc16773.

[7] Balter S, Hopewell JW, Miller DL, Wagner LK, Zelefsky MJ. Fluoroscopically guided interventional procedures: a review of radiation effects on patients' skin and hair. Radiology 2010;254:326-41. https://doi.org/10.1148/ radiol.2542082312

[8] Albert MD, Bucher NL. Latent injury and repair in rat liver induced to regenerate at intervals after X-radiation. Cancer. Res. 1960;20:1514.

[9] Benson R, Madan R, Kilambi R, Chander S. Radiation induced liver disease: a clinical update. J. Egypt. Natl. Canc. Inst. 2016;28:7-11. https://doi.org/ 10.1016/j.jnci.2015.08.001.

[10] Dawson LA, Normolle D, Balter JM, McGinn CJ, Lawrence TS, Ten Haken RK. Analysis of radiation-induced liver disease using the Lyman NTCP model. Int. J. Radiat. Oncol. Biol. Phys. 2002;53:810-21. https://doi.org/10.1016/s0360-3016 (02)02846-8.

[11] ICRP. ICRP Statement on tissue reactions/Early and late effects of radiation in normal tissues and organs - threshold doses for tissue reactions in a radiation protection context. ICRP Publication 118. Ann. ICRP. 2012;41:1-322. https://doi. org /10.1016/j.icrp. 2012.02.001.

[12] IAEA. Dosimetry in diagnostic radiology: An international code of practice (Technical Report Series No. 457). Vienna: International Atomic Energy; 2007.

[13] A. Badal, F. Zafar, H. Dong, A. Badano. A real-time radiation dose monitoring system for patients and staff during interventional fluoroscopy using a GPUaccelerated Monte Carlo simulator and an automatic 3D localization system based on a depth camera. Medical Imaging 2013: Physics of Medical Imaging: International Society for Optics and Photonics; 2013. p. 866828. https://doi.org/ 10.1117/12.2008031

[14] Roser P, Zhong X, Birkhold A, Strobel N, Kowarschik M, Fahrig R, et al. Physicsdriven learning of $\mathrm{x}$-ray skin dose distribution in interventional procedures. Med. Phys. 2019;46:4654-65. https://doi.org/10.1002/mp.13758.

[15] Song SJ, Liu CZ, Zhang ML. Radiation dose and mortality risk to children undergoing therapeutic interventional cardiology. Acta. Radiol. 2015;56:867-72. https://doi.org/10.1177/0284185114542459.

[16] Balaguru D, Rodriguez M, Leon S, Wagner LK, Beasley CW, Sultzer A, et al.

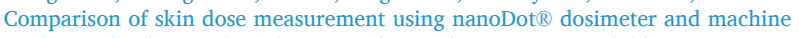
readings of radiation dose during cardiac catheterization in children. Ann. Pediatr. Cardiol. 2018:11:12-6.

[17] Kawasaki T, Fujii K, Akahane K. Estimation of organ and effective doses for neonate and infant diagnostic cardiac catheterizations. Am. J. Roentgenol. 2015; 205:599-603. https://doi.org/10.2214/ajr.14.13852.

[18] Glennie D, Connolly BL, Gordon C, Glennie D, Connolly BL, Gordon C. Entrance skin dose measured with MOSFETs in children undergoing interventional radiology procedures. Pediatr. Radiol. 2008;38:1180-7. https://doi.org/ 10.1007/s00247-008-0966-y.

[19] Safari MJ, Wong JHD, Kadir KAA, Thorpe NK, Cutajar DL, Petasecca M, et al. Real-time eye lens dose monitoring during cerebral angiography procedures. Eur. Radiol. 2016;26:79-86. https://doi.org/10.1007/s00330-015-3818-9.

[20] Pasquino M, Cutaia C, Poli M, Valero C, Peroni G, De Benedictis M, et al. Patient's Peak Skin Dose evaluation using Gafchromic films in interventional cardiology procedures and its correlation with other dose indicators. Phys. Medica. 2018;53: 103-7. https://doi.org/10.1016/j.ejmp.2018.08.017.

[21] Goertz L, Tsiamas P, Karellas A, Sajo E, Zygmanski P. Monte Carlo simulation of a prototypical patient dosimetry system for fluoroscopic procedures. Phys. Med. Biol. 2015;60:5891. https://doi.org/10.1088/0031-9155/60/15/5891.

[22] Guberina N, Lechel U, Forsting M, Monninghoff C, Dietrich U, Ringelstein A. Dose comparison of classical 2-plane DSA and 3D rotational angiography for the assessment of intracranial aneurysms. Neuroradiology 2016;58:673-8. https:// doi.org/10.1007/s00234-016-1671-4.

[23] Compagnone G, Giampalma E, Domenichelli S, Renzulli M, Golfieri R. Calculation of conversion factors for effective dose for various interventional radiology procedures. Med. Phys. 2012;39:2491-8. https://doi.org/10.1118/1.3702457. 
[24] Khodadadegan Y, Zhang M, Pavlicek W, Paden RG, Chong B, Huettl EA, et al. Validation and initial clinical use of automatic peak skin dose localization with fluoroscopic and interventional procedures. Radiology 2013;266:246-55. https://doi.org/10.1148/radiol.12112295.

[25] Jarvinen H, Farah J, Siiskonen T, Ciraj-Bjelac O, Dabin J, Carinou E, et al. Feasibility of setting up generic alert levels for maximum skin dose in fluoroscopically guided procedures. Phys. Medica. 2018;46:67-74. https://doi. org/10.1016/j.ejmp.2018.01.010.

[26] IEC. Medical Electrical Equipment-part 2-43: Particular Requirements for the Safety of X-ray Equipment for Interventional Procedures (IEC 60601-2-43 ed2.0) Geneva: International Electrotechnical Commission. 2010.

[27] FDA. Code of Federal Regulations, Title 21, Volume 8, Performance Standards for Ionizing Radiation Emitting Products: Fluoroscopic Equipment (21CFR1020.32). Retrieved from the U.S. Food and Drug Administration website: https://www. accessdata.fda.gov/scripts/cdrh/cfdocs/cfcfr/CFRSearch.cfm?fr=1020.32. 2019

[28] Johnson P, Borrego D, Balter S, Johnson K, Siragusa D, Bolch WE. Skin dose mapping for fluoroscopically guided interventions. Med. Phys. 2011;38:5490-9. https://doi.org/10.1118/1.3633935.

[29] Khodadadegan Y, Zhang MH, Pavlicek W, Paden RG, Chong B, Schueler BA, et al. Automatic Monitoring of Localized Skin Dose with Fluoroscopic and Interventional Procedures. J. Digit. Imaging. 2011;24:626-39. https://doi.org/ 10.1007/s10278-010-9320-7.

[30] den Boer A, de Feijter PJ, Serruys PW, Roelandt J. Real-time quantification and display of skin radiation during coronary angiography and intervention. Circulation 2001;104:1779-84. https://doi.org/10.1161/hc4001.097057.

[31] Bednarek DR, Barbarits J, Rana VK, Nagaraja SP, Josan MS, Rudin S. Verification of the performance accuracy of a real-time skin-dose tracking system for interventional fluoroscopic procedures. Pro SPIE Int Soc Opt. Eng. 2011;7961.

[32] Boujan F, Clauss N, Santos E, Boon S, Schouten G, Mertz L, et al. A new method of real-time skin dose visualization. Clinical evaluation of fluoroscopically guided interventions. Neuroradiology 2014;56:971-6. https://doi.org/10.1007/s00234 014-1401-8.

[33] Greffier J, Ty CVN, Bonniaud G, Moliner G, Ledermann B, Schmutz L, et al Assessment of peak skin dose in interventional cardiology: a comparison between Gafchromic film and dosimetric software em. dose. Phys. Medica. 2017;38:16-22. https://doi.org/10.1016/j.ejmp.2017.05.044.

[34] Bordier C, Klausz R, Desponds L. Accuracy of a dose map method assessed in clinical and anthropomorphic phantom situations using Gafchromic films. Radiat. Prot. Dosim. 2015;165:244-9. https://doi.org/10.1093/rpd/ncv034.

[35] Colombo PE, Rottoli F, Felisi M, De Mattia C, Riga S, Sutto M, et al. Validation of a dose tracking software for skin dose map calculation in interventional radiology. Phys. Medica. 2020;72:122-32. https://doi.org/10.1016/j.ejmp.2020.03.008.

[36] Andreo P. Monte Carlo techniques in medical radiation physics. Phys. Med. Biol 1991;36:861. https://doi.org/10.1088/0031-9155/36/7/001.

[37] Halton JH. A retrospective and prospective survey of the Monte Carlo method. Siam. Rev. 1970;12:1-63. https://doi.org/10.1137/1012001.

[38] James F. Monte Carlo theory and practice. Rep. Prog. Phys. 1980;43:1145. https://doi.org/10.1088/0034-4885/43/9/002.

[39] Kim CH, Jeong JH, Bolch WE, Cho KW, Hwang SB. A polygon-surface reference Korean male phantom (PSRK-Man) and its direct implementation in Geant4 Monte Carlo simulation. Phys. Med. Biol. 2011;56:3137-61. https://doi.org/ 10.1088/0031-9155/56/10/016.

[40] Zhang J, Xu XG, Shi C, Fuss M. Development of a geometry-based respiratory motion-simulating patient model for radiation treatment dosimetry. J. Appl. Clin. Med. Phys. 2008;9:16-28. https://doi.org/10.1120/jacmp.v9i1.2700.

[41] Xu XG. Computational phantoms for radiation dosimetry: a 40-Year history of evolution. In: Xu XG, Eckerman KF, editors. Handbook of Anatomical Models For Radiation Dosimetry (Series In Medical Physics And Biomedical Engineering). New York: CDC Press A Taylor \& Francis Groups; 2010. p. 3-42.

[42] Snyder WS, Snyder WS, Fisher Jr HL, Ford MR, Warner GG. Estimates of absorbed fractions for monoenergetic photon sources uniformly distributed in various organs of a heterogeneous phantom. J. Nucl. Med. 1969;7-52.

[43] Lee C, Lee C, Park SH, Lee JK. Development of the two Korean adult tomographic computational phantoms for organ dosimetry. Med. Phys. 2006;33:380-90. https://doi.org/10.1118/1.2161405.

[44] Nagaoka T, Watanabe S, Sakurai K, Kunieda E, Watanabe S, Taki M, et al. Development of realistic high-resolution whole-body voxel models of Japanese adult males and females of average height and weight, and application of models to radio-frequency electromagnetic-field dosimetry. Phys. Med. Biol. 2003;49:1. https://doi.org/10.1088/0031-9155/49/1/001.

[45] Kim CH, Choi SH, Jeong JH, Lee C, Chung MS. HDRK-Man: a whole-body voxel model based on high-resolution color slice images of a Korean adult male cadaver. Phys. Med. Biol. 2008;53:4093-106. https://doi.org/10.1088/0031 9155/53/15/006.

[46] Lee C, Williams JL, Lee C, Bolch WE. The UF series of tomographic computational phantoms of pediatric patients. Med. Phys. 2005;32:3537-48. https://doi.org/ 10.1118/1.2107067.

[47] Yeom YS, Choi C, Han H, Lee H, Shin B, Nguyen TT, et al. Dose coefficients of mesh-type ICRP reference computational phantoms for idealized external exposures of photons and electrons. Nucl. Eng. Technol. 2019;51:843-52. https://doi.org/10.1016/j.net.2018.12.006.

[48] Gosselin M-C, Neufeld E, Moser H, Huber E, Farcito S, Gerber L, et al. Development of a new generation of high-resolution anatomical models for medical device evaluation: the Virtual Population 3.0. Phys. Med. Biol. 2014. https://doi.org/10.1088/0031-9155/59/18/5287.
[49] Segars W, Bond J, Frush J, Hon S, Eckersley C, Williams CH, et al. Population of anatomically variable 4D XCAT adult phantoms for imaging research and optimization. Med. Phys. 2013;40:043701. https://doi.org/10.1118/1.4794178.

[50] Xie T, Kuster N, Zaidi H. Computational hybrid anthropometric paediatric phantom library for internal radiation dosimetry. Phys. Med. Biol. 2017;62:3263. https://doi.org/10.1088/1361-6560/aa63d0.

[51] Johnson PB, Whalen SR, Wayson M, Juneja B, Lee C, Bolch WE. Hybrid patientdependent phantoms covering statistical distributions of body morphometry in the US adult and pediatric population. Proc. IEEE. 2009;97:2060-75. https://doi. org/10.1109/JPROC.2009.2032855.

[52] Marshall EL, Borrego D, Tran T, Fudge JC, Bolch WE. Evaluation of the UF/NCI hybrid computational phantoms for use in organ dosimetry of pediatric patients undergoing fluoroscopically guided cardiac procedures. Phys. Med. Biol. 2018; 63:055006. https://doi.org/10.1088/1361-6560/aaad1d.

[53] Caon M. Voxel-based computational models of real human anatomy: a review. Radiat. Environ. Biophys. 2004;42:229-35. https://doi.org/10.1007/s00411003-0221-8.

[54] Xu XG. An exponential growth of computational phantom research in radiation protection, imaging, and radiotherapy: a review of the fifty-year history. Phys. Med. Biol. 2014;59:R233-302. https://doi.org/10.1088/0031-9155/59/18/ r233.

[55] Zankl M, Becker J, Lee C, Bolch W, Yeom Y, Kim CH. Computational phantoms, ICRP/ICRU, and further developments. Ann. ICRP. 2018;47:35-44. https://doi. org/10.1177/0146645318756229.

[56] Yeom YS, Jeong JH, Han MC, Kim CH. Tetrahedral-mesh-based computational human phantom for fast Monte Carlo dose calculations. Phys. Med. Biol. 2014;59: 3173-85. https://doi.org/10.1088/0031-9155/59/12/3173.

[57] Rogers DW. Fifty years of Monte Carlo simulations for medical physics. Phys. Med. Biol. 2006;51:R287-301. https://doi.org/10.1088/0031-9155/51/13/r17.

[58] Werner CJ. MCNP Users Manual-Code Version 6.2. Los Alamos National Laboratory, Los Alamos. 2017.

[59] C. Werner J. Bull C. Solomon F. Brown G. McKinney M. Rising et al. MCNP6. 2 release notes Los Alamos National Laboratory, report LA-UR-18-20808. 2018.

[60] I. Kawrakow E. Mainegra-Hing D. Rogers F. Tessier B. Walters The EGSnrc Code System: Monte Carlo simulation of electron and photon transport Technical Report PIRS-701. National Research Council Canada 2017.

[61] Agostinelli S, Allison J, Ka A, Apostolakis J, Araujo H, Arce P, et al. GEANT4-a simulation toolkit. Nucl. Instrum. Methods. Phys. Res. A. 2003;506:250-303. https://doi.org/10.1016/S0168-9002(03)01368-8.

[62] Allison J, Amako K, Apostolakis J, Araujo H, Dubois PA, Asai M, et al. Geant4 developments and applications. IEEE Trans. Nucl Sci. 2006;53:270-8. https://doi. org/10.1109/TNS.2006.869826.

[63] Agency NE. PENELOPE 2018: A code system for Monte Carlo simulation of electron and photon transport.

[64] Sechopoulos I, Ali ES, Badal A, Badano A, Boone JM, Kyprianou IS, et al. Monte Carlo reference data sets for imaging research: Executive summary of the report of AAPM Research Committee Task Group 195. Med. Phys. 2015;42:5679-91. https://doi.org/10.1118/1.4928676.

[65] Poole CM, Cornelius I, Trapp JV, Langton CM. Fast tessellated solid navigation in GEANT4. IEEE Trans. Nucl. Sci. 2012;59:1695-701. https://doi.org/10.1109/ TNS. 2012.2197415.

[66] Han MC, Yeom YS, Kim CH, Kim S, Sohn JW. New approach based on tetrahedralmesh geometry for accurate 4D Monte Carlo patient-dose calculation. Phys. Med. Biol. 2015;60:1601. https://doi.org/10.1088/0031-9155/60/4/1601.

[67] Constantin M, Constantin DE, Keall PJ, Narula A, Svatos M, Perl J. Linking computer-aided design (CAD) to Geant4-based Monte Carlo simulations for precise implementation of complex treatment head geometries. Phys. Med. Biol. 2010;55:N211. https://doi.org/10.1088/0031-9155/55/8/n03.

[68] Han MC, Kim CH, Jeong JH, Yeom YS, Kim S, Wilson PP, et al. DagSolid: a new Geant4 solid class for fast simulation in polygon-mesh geometry. Phys. Med. Biol. 2013;58:4595. https://doi.org/10.1088/0031-9155/58/13/4595.

[69] Omar A, Bujila R, Fransson A, Andreo P, Poludniowski G. A framework for organ dose estimation in X-ray angiography and interventional radiology based on doserelated data in DICOM structured reports. Phys. Med. Biol. 2016;61:3063-83. https://doi.org/10.1088/0031-9155/61/8/3063.

[70] Jones DG, Wall BF. Organ Doses From Organ Doses From Medical X-Ray Examinations Calculated Using Monte Carlo Techniques. Didcot: National Radiological Protection Board; 1985.

[71] LeHeron JC. XDOSE: A user's guide. Chirstchurch, New Zealand: National Radiation Laboratory, Ministry of Health; 1994.

[72] NBH. Eff-Dose software: Estimation of effective and organ doses Bronshoj, Denmark. 1995.

[73] M. Tapiovaara, M. Lakkisto, A. Servomaa, PCXMC. A PC-based Monte Carlo program for calculating patient doses in medical X-ray examinations. Finnish Centre for Radiation and Nuclear Safety (STUK); 1997. https://doi.org/10.1093/ jicru/ndi034.

[74] Rannikko S, Ermakov I, Lampinen JS, Toivonen M, Karila KT, Chervjakov A. Computing patient doses of X-ray examinations using a patient size- and sexadjustable phantom. Brit. J. Radiol. 1997;70:708-18. https://doi.org/10.1259/ bjr.70.835.9245883.

[75] Golikov V, Barkovski A, Baryshkov N, Vlasov A. Assessment of radiation doses to the patients in medical X-ray diagnosis. Radiation protection for humans and society in tomorrow's Europe Joint meeting of OeVS (Oesterreichischer Verband fuer Strahlenschutz) and FS (Fachverband fuer Strahlenschutz) 33 FS Annual Meeting 2001. 
[76] Kramer R, Khoury HJ, Vieira JW. CALDose_X-a software tool for the assessment of organ and tissue absorbed doses, effective dose and cancer risks in diagnostic radiology. Phys. Med. Biol. 2008;53:6437-59. https://doi.org/10.1088/00319155/53/22/011.

[77] Kramer R, Vieira J, Khoury H, de Andrade LF. MAX meets ADAM: a dosimetric comparison between a voxel-based and a mathematical model for external exposure to photons. Phys. Med. Biol. 2004;49:887. https://doi.org/10.1088/ 0031-9155/49/6/002.

[78] D. Borrego, E.M. Lowe, C.M. Kitahara, C. Lee. Assessment of PCXMC for patients with different body size in chest and abdominal $\mathrm{x}$ ray examinations: a Monte Carlo simulation study. Phys Med Biol. 2018;63:065015. https://dx.doi.org/ 10.1088\%2F1361-6560\%2Faab13e.

[79] Han EY, Bolch WE, Eckerman KF. Revisions to the ORNL series of adult and pediatric computational phantoms for use with the MIRD schema. Health. Phys. 2006;90:337-56. https://doi.org/10.1097/01.hp.0000192318.13190.c4.

[80] Karimian A, Nikparvar B, Jabbari I. Assessment of physician and patient (child and adult) equivalent doses during renal angiography by Monte Carlo. Radiat. Prot. Dosim. 2014;162:120-4. https://doi.org/10.1093/rpd/ncu242.

[81] Smans K, Struelens L, Hoornaert MT, Bleeser F, Buls N, Berus D, et al. A study of the correlation between dose area product and effective dose in vascular radiology. Radiat. Prot. Dosim. 2008;130:300-8. https://doi.org/10.1093/rpd/ non 050 .

[82] Stratakis J, Damilakis J, Tsetis D, Gourtsoyiannis N. Radiation dose and risk from fluoroscopically guided percutaneous transluminal angioplasty and stenting in the abdominal region. Eur. Radiol. 2007;17:2359-67. https://doi.org/10.1007/ s00330-007-0632-z.

[83] Stratakis J, Damilakis J, Hatzidakis A, Perisinakis K, Gourtsoyiannis N. Radiation dose and risk from fluoroscopically guided percutaneous transhepatic biliary procedures. J. Vasc. Interv. Radiol. 2006;17:77-84. https://doi.org/10.1097/01. rvi.0000188754.97465.13.

[84] Bacher K, Bogaert E, Lapere R, De Wolf D, Thierens H. Patient-specific dose and radiation risk estimation in pediatric cardiac catheterization. Circulation 2005; 111:83-9. https://doi.org/10.1161/01.cir.0000151098.52656.3a.

[85] van de Putte S, Verhaegen F, Taeymans Y, Thierens H. Correlation of patient skin doses in cardiac interventional radiology with dose-area product. Br. J. Radiol. 2000;73:504-13. https://doi.org/10.1259/bjr.73.869.10884747.

[86] Kramer R, Zankl M, Williams G, Drexler G. The calculation of dose from externa photon exposures using reference human phantoms and Monte Carlo methods: Part I. The male (ADAM) and female (EVA) adult mathematical phantoms. GSFReport S-885. Neuherberg-Muenchen: Institut für Strahlenschutz, GSFForschungszentrum für Umwelt und Gesundheit; 1982.

[87] Vetter S, Schultz FW, Strecker EP, Zoetelief J. Optimisation strategies and justification: an example in uterine artery embolisation for fibroids. Radiat. Prot. Dosim. 2005;117:50-3. https://doi.org/10.1093/rpd/nci717.

[88] Schultz FW, Geleijns J, Spoelstra FM, Zoetelief J. Monte Carlo calculations for assessment of radiation dose to patients with congenital heart defects and to staf during cardiac catheterizations. Br. J. Radiol. 2003;76:638-47. https://doi.org/ $10.1259 / \mathrm{bjr} / 21647806$

[89] Kemerink GJ, Kicken PJH, Schultz FW, Zoetelief J, van Engelshoven JMA. Patient dosimetry in abdominal arteriography. Phys. Med. Biol. 1999;44:1133-45. https://doi.org/10.1088/0031-9155/44/5/002.

[90] Kicken PJH, Zankl M, Kemerink GJ. Patient dosimetry in arteriography of the lower limbs. Part II: Dose conversion coefficients, organ doses and effective dose. Radiat. Prot. Dosim. 1999;81:37-45. https://doi.org/10.1093/oxfordjournals. rpd.a032568.

[91] Xu X, Chao T, Bozkurt A. VIP-Man: an image-based whole-body adult male model constructed from color photographs of the Visible Human Project for multiparticle Monte Carlo calculations. Health. Phys. 2000;78:476-86. https://doi. org/10.1097/00004032-200005000-00003.

[92] Bozkurt A, Bor D. Simultaneous determination of equivalent dose to organs and tissues of the patient and of the physician in interventional radiology using the Monte Carlo method. Phys. Med. Biol. 2007;52:317-30. https://doi.org/ 10.1088/0031-9155/52/2/001.

[93] Park SH, Lee C, Lee JK. Organ absorbed doses and effective doses to the patient and the medical staff in interventional radiology calculated from voxel phantom. J. Nucl. Sci. Technol. 2008;309-12. https://doi.org/10.1080/ 00223131.2008 .10875850$.

[94] Petoussi-Henss N, Zankl M, Fill U, Regulla D. The GSF family of voxel phantoms. Phys. Med. Biol. 2001;47:89. https://doi.org/10.1088/0031-9155/47/1/307.

[95] Zankl M, Fill U, Petoussi-Henss N, Regulla D. Organ dose conversion coefficients for external photon irradiation of male and female voxel models. Phys. Med. Biol. 2002;47:2367. https://doi.org/10.1088/0031-9155/47/14/301.

[96] Roser P, Birkhold A, Zhong X, Ochs P, Stepina E, Kowarschik M, et al. Pitfalls in interventional X-ray organ dose assessment-combined experimental and computational phantom study: application to prostatic artery embolization. Int. J.
Comput. Assist. Radiol. Surg. 2019;14:1859-69. https://doi.org/10.1007/ s11548-019-02037-6.

[97] Lee C, Lodwick D, Hasenauer D, Williams JL, Lee C, Bolch WE. Hybrid computational phantoms of the male and female newborn patient: NURBS-based whole-body models. Phys. Med. Biol. 2007;52:3309. https://doi.org/10.1088/ 0031-9155/52/12/001.

[98] Johnson P, Geyer A, Borrego D, Ficarrotta K, Johnson K, Bolch WE. The impact of anthropometric patient-phantom matching on organ dose: a hybrid phantom study for fluoroscopy guided interventions. Med. Phys. 2011;38:1008-17. https://doi.org/10.1118/1.3544353.

[99] Johnson P, Lee C, Johnson K, Siragusa D, Bolch WE. The influence of patient size on dose conversion coefficients: a hybrid phantom study for adult cardiac catheterization. Phys. Med. Biol. 2009;54:3613-29. https://doi.org/10.1088/ 0031-9155/54/12/001.

[100] Cassola V, de Melo LV, Kramer R, Khoury H. FASH and MASH: female and male adult human phantoms based on polygon mesh surfaces: I. Development of the anatomy. Phys. Med. Biol. 2009. https://doi.org/10.1088/0031-9155/55/1/009.

[101] Garzón W, Kramer R, Khoury H, De Barros V, Andrade G. Estimation of organ doses to patients undergoing hepatic chemoembolization procedures. J. Radiol Prot. 2015;35:629. https://doi.org/10.1088/0952-4746/35/3/629.

[102] Santos WS, Neves LP, Perini AP, Belinato W, Caldas LVE, Carvalho AB, et al. Exposures in interventional radiology using Monte Carlo simulation coupled with virtual anthropomorphic phantoms. Phys. Medica. 2015;31:929-33. https://doi. org/10.1016/j.ejmp.2015.06.011.

[103] Geyer AM, O'Reilly S, Lee C, Long DJ, Bolch WE. The UF/NCI family of hybrid computational phantoms representing the current US population of male and fe7male children, adolescents, and adults-application to CT dosimetry. Phys. Med. Biol. 2014;59:5225. https://doi.org/10.1088/0031-9155/59/18/5225.

[104] Borrego D, Siragusa DA, Balter S, Bolch WE. A hybrid phantom system for patient skin and organ dosimetry in fluoroscopically guided interventions. Med. Phys. 2017;44:4928-42. https://doi.org/10.1002/mp.12419.

[105] Marshall EL, Borrego D, Fudge JC, Rajderkar D, Bolch WE. Organ doses in pediatric patients undergoing cardiac-centered fluoroscopically guided interventions: comparison of three methods for computational phantom alignment. Med. Phys. 2018;45:3926-38. https://doi.org/10.1002/mp.13044.

[106] Huet C, Entine F, Bassinet C, Dondey M, Dreuil S, Georges J-L, et al. SESAME: a tool for numerical dosimetric reconstruction of patients overexposures in interventional radiology. Radiat. Prot. Dosim. 2019;185:231-8. https://doi.org/ $10.1093 / \mathrm{rpd} / \mathrm{ncz} 004$.

[107] Huo WL, Pi YF, Feng M, Qi YP, Gao YM, Caracappa PF, et al. VirtualDose-IR: a cloud-based software for reporting organ doses in interventional radiology. Phys. Med. Biol. 2019;64:22. https://doi.org/10.1088/1361-6560/ab0bd5.

[108] Huo W, Feng M, Pi Y, Chen Z, Gao Y, Xu XG. Monte Carlo calculations for reporting patient organ doses from interventional radiology. EPJ Web of Conf: EDP Sciences; 2017. p. 04016. https://doi.org/10.1051/epjconf/201715304016.

[109] Zhang J, Na YH, Caracappa PF, Xu XG. RPI-AM and RPI-AF, a pair of mesh-based, size-adjustable adult male and female computational phantoms using ICRP-89 parameters and their calculations for organ doses from monoenergetic photon beams. Phys. Med. Biol. 2009;54:5885. https://doi.org/10.1088/0031-9155/54/ 19/015.

[110] Na YH, Zhang B, Zhang J, Caracappa PF, Xu XG. Deformable adult human phantoms for radiation protection dosimetry: anthropometric data representing size distributions of adult worker populations and software algorithms. Phys. Med. Biol. 2010;55:3789. https://doi.org/10.1088/0031-9155/55/13/015.

[111] Touileb Y, Manescu P, Ladjal H, Azencot J, Beuve M, Shariat B. Motion-induced Monte Carlo dose calculation using deformable tetrahedral meshes. 2016 IEEE 13th International Symposium on Biomedical Imaging (ISBI): IEEE; 2016. p. 1257-60. https://doi.org/10.1109/ISBI.2016.7493495.

[112] Chen P, Barner KE, Steiner KV. A displacement driven real-time deformable model for haptic surgery simulation. 2006 14th Symposium on Haptic Interfaces for Virtual Environment and Teleoperator Systems: IEEE; 2006. p. 499-505. https://doi.org/10.1109/HAPTIC.2006.1627099.

[113] J. Park, D. Metaxas, L. Axel. Analysis of left ventricular wall motion based on volumetric deformable models and MRI-SPAMM. Center for Human Modeling and Simulation. 1996:99. https://doi.org/10.1016/S1361-8415(01)80005-0.

[114] Segars WP, Lalush DS, Tsui BM. Modeling respiratory mechanics in the MCAT and spline-based MCAT phantoms. IEEE Trans. Nucl. Sci. 2001;48:89-97. https://doi. org/10.1109/23.910837.

[115] Barnaoui S, Rehel JL, Baysson H, Boudjemline Y, Girodon B, Bernier MO, et al. Local reference levels and organ doses from pediatric cardiac interventional procedures. Pediatr. Cardiol. 2014;35:1037-45. https://doi.org/10.1007/ s00246-014-0895-5.

[116] Lee CS, Lee JK. Computational anthropomorphic phantoms for radiation protection dosimetry: evolution and prospects. Nucl. Eng. Technol. 2006;38: 239-50. 